\title{
Association between hydroxocobalamin administration and acute kidney injury after smoke inhalation: a multicenter retrospective study
}

François Dépret ${ }^{1,2,3,4}$, Clément Hoffmann ${ }^{5}$, Laura Daoud ${ }^{1}$, Camille Thieffry ${ }^{6}$, Laure Monplaisir ${ }^{1}$, Jules Creveaux ${ }^{5}$, Djillali Annane ${ }^{7}$, Erika Parmentier ${ }^{6}$, Daniel Mathieu ${ }^{6}$, Sandrine Wiramus $^{8}$, Dominique Demeure Dlt Latte ${ }^{9}$, Aubin Kpodji ${ }^{10}$, Julien Textoris ${ }^{11}$, Florian Robin ${ }^{12}$, Kada Klouche ${ }^{13}$, Emmanuel Pontis ${ }^{14}$, Guillaume Schnell ${ }^{15}$, François Barbier ${ }^{16}$, Jean-Michel Constantin ${ }^{17}$, Thomas Clavier ${ }^{18,19}$, Damien du Cheyron ${ }^{20}$, Nicolas Terzi ${ }^{21}$, Bertrand Sauneuf ${ }^{22}$, Emmanuel Guerot ${ }^{23,24}$, Thomas Lafon ${ }^{25,26}$, Alexandre Herbland ${ }^{27}$, Bruno Megarbane ${ }^{28}$, Thomas Leclerc $^{4}$, Vincent Mallet ${ }^{29}$, Romain Pirracchio ${ }^{30}$ and Matthieu Legrand ${ }^{1,2,3,5,31^{*}}$ (D)

\section{Abstract}

Background: The use of hydroxocobalamin has long been advocated for treating suspected cyanide poisoning after smoke inhalation. Intravenous hydroxocobalamin has however been shown to cause oxalate nephropathy in a single-center study. The impact of hydroxocobalamin on the risk of acute kidney injury (AKI) and survival after smoke inhalation in a multicenter setting remains unexplored.

Methods: We conducted a multicenter retrospective study in 21 intensive care units (ICUs) in France. We included patients admitted to an ICU for smoke inhalation between January 2011 and December 2017. We excluded patients discharged at home alive within $24 \mathrm{~h}$ of admission. We assessed the risk of AKI (primary endpoint), severe AKI, major adverse kidney (MAKE) events, and survival (secondary endpoints) after administration of hydroxocobalamin using logistic regression models.

Results: Among 854 patients screened, 739 patients were included. Three hundred six and 386 (55.2\%) patients received hydroxocobalamin. Mortality in ICU was 32.9\% $(n=243)$. Two hundred eighty-eight (39\%) patients developed AKI, including 186 (25.2\%) who developed severe AKI during the first week. Patients who received hydroxocobalamin were more severe and had higher mortality $(38.1 \%$ vs $27.2 \%, p=0.0022)$. The adjusted odds ratio (95\% confidence interval) of AKI after intravenous hydroxocobalamin was $1.597(1.055,2.419)$ and $1.772(1.137$, 2.762) for severe AKI; intravenous hydroxocobalamin was not associated with survival or MAKE with an adjusted odds ratio $(95 \%$ confidence interval) of $1.114(0.691,1.797)$ and $0.784(0.456,1.349)$ respectively.

Conclusion: Hydroxocobalamin was associated with an increased risk of AKI and severe AKI but was not associated with survival after smoke inhalation.

Trial registration: ClinicalTrials.gov, NCT03558646

Keywords: Smoke inhalation, Acute kidney injury, Intensive care unit, Mortality, Burn, Hydroxocobalamin

\footnotetext{
*Correspondence: matthieu.m.legrand@gmail.com

'Department of Anesthesiology and Critical Care and Burn Unit, AP-HP, GH

Saint Louis-Lariboisière, Paris, France

2 UMR INSERM 942, Institut National de la Santé et de la Recherche Médicale

(INSERM), Paris, France

Full list of author information is available at the end of the article
}

(c) The Author(s). 2019 Open Access This article is distributed under the terms of the Creative Commons Attribution 4.0 International License (http://creativecommons.org/licenses/by/4.0/), which permits unrestricted use, distribution, and reproduction in any medium, provided you give appropriate credit to the original author(s) and the source, provide a link to the Creative Commons license, and indicate if changes were made. The Creative Commons Public Domain Dedication waiver (http://creativecommons.org/publicdomain/zero/1.0/) applies to the data made available in this article, unless otherwise stated. 


\section{Introduction}

Patients with smoke inhalation are at a high risk of death or major morbidities. Cyanide is a documented cause for rapid death after intoxication from smoke [1]. Several cyanide antidotes have been proposed (i.e., sodium nitrite, amyl nitrite, sodium thiosulfate, 4-dimethylaminophenol, dicobalt edetate, and hydroxocobalamin) with utilization varying across countries [2]. Several experts suggested using hydroxocobalamin as the first-line treatment after suspected cyanide intoxication due to its perceived good safety profile [3]. However, other experts raised concerns about liberalizing the use of hydroxocobalamin after smoke inhalation due to a lack of data on both efficacy and tolerance. They have called for additional investigations [4, 5].

Recently, nephrotoxicity of hydroxocobalamin due to oxalate nephropathy was reported in a single-center study among burn patients [4]. The objective of this cohort study was to assess the association between the use of hydroxocobalamin and the risk of acute kidney injury (AKI) and death in intensive care unit (ICU) patients with smoke inhalation.

\section{Methods}

\section{Study population and settings}

We conducted a retrospective, multicenter study in 21 ICUs in France. All consecutive adult ( $\geq 18$ years old) patients admitted between January 2011 and December 2017 with the final diagnosis of smoke inhalation were included in this study. Patients discharged alive at home within $24 \mathrm{~h}$ from admission (reflecting absence of severity) were excluded. Patient files were retrieved using our national coding for smoke inhalation injury (code CIM T599 for all patients and associated: X00.0, X 09.0, X09.9, X47.0, X47.08, X47.9, X67.0, X67.9, T58) (Additional file 1: Table S1). This academic investigator-driven study was registered at ClinicalTrials.gov, NCT03558646. The study protocol was approved by our local research ethical committee (Comité de Protection des Personnes 2013/17NICB). The use of patient's data was allowed in cases of death and/or when proxies could not be contacted.

\section{Primary outcome}

The primary outcome was AKI. AKI was defined according to Kidney Disease Improving Global Outcome (KDIGO) within 7 days following admission using the serum creatinine criteria [6].

\section{Secondary outcome}

Secondary outcomes were severe AKI (severe AKI defined patients by AKI stage 2 or 3), major associated kidney events (MAKE) in the ICU, which includes death and/or renal replacement therapy (RRT), and/or persistent AKI at ICU discharge. Persistent AKI was defined as an elevated SCreat level from baseline by $>1.5$-fold or $>0.3 \mathrm{mg} / \mathrm{dL}$ $(26.3 \mu \mathrm{mol} / \mathrm{L})$ at ICU discharge or RRT at ICU discharge and survival in the ICU.

\section{Data collections and definitions}

Data were collected through a standardized case report form. Each form was manually encoded in each participating center using the initials and year of birth of the patient. Admission serum creatinine (SCreat) was used for baseline SCreat. Severe burn was defined as total body surface area (TBSA) burn $\geq 20 \%$ and/or deep TBSA burn $\geq 10 \%$ with organ support on admission (i.e., mechanical ventilation or need for vasopressors) [7]. When a fiber-optic bronchoscopy was performed, inhalation injury was classified according to fiber-optic bronchoscopy inhalation injury classification [8].

\section{Sample size and statistical analysis}

Due to the exploratory design of this study, no sample size could be calculated. Categorical variables were presented using percentages and counts, and continuous variables were presented using means and standard deviations or medians with the 25th and 75 th percentiles. Categorical variables were compared using the chi-square test or Fisher's exact test as appropriate. Continuous variables were compared using the Student $t$ test or the Mann-Whitney $U$ test as appropriate.

Actuarial mortality was plotted using the KaplanMeier estimator. Administrative censoring was applied at day 90. The impact of hydroxocobalamin administration on AKI was estimated using a multivariate logistic regression model adjusting age, comorbidities, aminoglycoside, vancomycin and iodine contrast agent utilization during hospitalization, peak value of creatinine phosphokinase, prehospital cardiac arrest, prehospital minimal GCS, severe burn, initial sequential organ failure assessment (SOFA) score without the renal item, lactate at admission, need for catecholamine infusion at admission, the SAPS2 score calculated over the first $24 \mathrm{~h}$, the interaction between hydroxocobalamin administration and prehospital cardiac arrest, and the center. The impact of hydroxocobalamin administration on secondary outcomes (severe AKI, MAKE, survival) was estimated using a multivariate logistic regression model adjusting for the same confounders. An interaction term between prehospital cardiac arrest and hydroxocobalamin was also introduced in the model. Odds ratios were provided together with their $95 \%$ confidence intervals. 
Table 1 Comparison between patients with or without hydroxocobalamin

\begin{tabular}{|c|c|c|c|c|}
\hline Characteristics & All patients, $N=739$ & Hydroxocobalamin, $N=386$ & No hydroxocobalamin, $N=353$ & $p$ \\
\hline \multicolumn{5}{|l|}{ At admission } \\
\hline - Age in years & $50(36-63)$ & $50(38-62)$ & $48(33-64)$ & 0.4858 \\
\hline - Sex female, n (\%) & $271(36.7)$ & $140(36.3)$ & $131(37.1)$ & 0.9335 \\
\hline - BMl in $\mathrm{kg} / \mathrm{m}^{2}$ & $25(22-28)$ & $24(22-28)$ & $25(22-28)$ & 0.2416 \\
\hline - Prehospital cardiac arrest (\%) & $46(6.2)$ & $42(10.9)$ & $4(1.1)$ & $<0.0001$ \\
\hline - Prehospital GSC /15 & $15(9-15)$ & $13(5-15)$ & $15(14-15)$ & $<0.0001$ \\
\hline \multicolumn{5}{|l|}{ Comorbidities } \\
\hline - CKD, n (\%) & $6(0.8)$ & $6(1.6)$ & $0(0)$ & 0.0315 \\
\hline - CHT, $n(\%)$ & $141(19.1)$ & $71(18.4)$ & $70(19.9)$ & 0.6872 \\
\hline - Diabetes mellitus, $n(\%)$ & $54(7.3)$ & $33(8.5)$ & $21(6)$ & 0.2243 \\
\hline - Peripheral artery disease, $n(\%)$ & $22(3)$ & $9(2.3)$ & $13(3.7)$ & 0.3882 \\
\hline$-\mathrm{CHF}, n(\%)$ & $33(4.5)$ & $20(5.2)$ & $13(3.7)$ & 0.4197 \\
\hline \multicolumn{5}{|l|}{ Burn characteristic } \\
\hline - Burn, $n(\%)$ & $577(78.1)$ & $286(74.1)$ & $291(82.4)$ & 0.0081 \\
\hline - TBSA \% & $20(3-47)$ & $15(0-45)$ & $24(6-50)$ & 0.0163 \\
\hline - Deep burn TBSA \% & $9(0-30)$ & $5(0-30)$ & $10(0-32)$ & 0.1985 \\
\hline SOFA at admission & $4(1-7)$ & $5(2-8)$ & $2(0-5)$ & $<0.0001$ \\
\hline MAP in $\mathrm{mmHg}$ & $86(72-101)$ & $86(68-101)$ & $86(73-101)$ & 0.4383 \\
\hline Vasopressors, $n(\%)$ & $226(30.6)$ & $153(39.6)$ & $73(20.7)$ & $<0.0001$ \\
\hline $\mathrm{HbCO} \%$ & $3.6(1.9-9.7)$ & $7(3-15)$ & $3(2-5)$ & $<0.0001$ \\
\hline \multicolumn{5}{|l|}{ Biological data } \\
\hline - Plasma lactate in mmol/L & $3.0(1.8-5.2)$ & $3.5(2.1-6)$ & $2.6(1.4-4.1)$ & $<0.0001$ \\
\hline - Serum creatinine at admission in $\mu \mathrm{mol} / \mathrm{L}$ & $76(59-101)$ & $82(63-106)$ & $71(56-93)$ & 0.0031 \\
\hline - Maximal serum creatinine in $\mu \mathrm{mol} / \mathrm{L}$ & $100(73-162)$ & $108(77-182)$ & $90(71-137)$ & 0.0027 \\
\hline Inhalation fibroscopic status, $n(\%)$ & $305(41.3)$ & $105(27.5)$ & $200(56.7)$ & $<0.0001$ \\
\hline - Grade $0, n$ & $1(0.1)$ & $0(0)$ & $1(0.3)$ & 1 \\
\hline - Grade 1, n & $121(16.4)$ & $31(8)$ & $90(25.5)$ & $<0.0001$ \\
\hline - Grade $2, n$ & $110(14.9)$ & $37(9.6)$ & $73(20.7)$ & $<0.0001$ \\
\hline - Grade $3, n$ & $73(9.9)$ & $37(9.6)$ & $36(10.2)$ & 0.8764 \\
\hline \multicolumn{5}{|l|}{ During ICU hospitalization } \\
\hline - In-ICU mortality, n (\%) & $243(32.9)$ & $147(38.1)$ & $96(27.2)$ & 0.0022 \\
\hline - AKI in the first week, $n(\%)$ & $288(39)$ & $166(43)$ & $122(34.6)$ & 0.0229 \\
\hline \multicolumn{5}{|l|}{ - Stage of AKI } \\
\hline - Stage 1, n (\%) & $102(13.8)$ & $52(13.5)$ & $50(14.2)$ & 0.8682 \\
\hline - Stage 2,n (\%) & $39(5.3)$ & $22(5.7)$ & $17(4.8)$ & 0.7099 \\
\hline - Stage $3, n(\%)$ & $147(19.9)$ & $92(23.8)$ & $55(15.6)$ & 0.0066 \\
\hline - Severe AKI, $n(\%)$ & $186(25.2)$ & $114(29.5)$ & $72(20.4)$ & 0.0055 \\
\hline RRT at day $7, n(\%)$ & $136(18.8)$ & $86(22.3)$ & $50(14.2)$ & 0.006 \\
\hline - RRT in ICU, $n(\%)$ & $183(24.8)$ & $107(27.7)$ & $76(21.5)$ & 0.0626 \\
\hline - MAKE, $n(\%)$ & $313(42.4)$ & $187(48.4)$ & $126(35.7)$ & 0.0006 \\
\hline - Shock in ICU, $n(\%)$ & $402(54.4)$ & $225(58.3)$ & $176(50)$ & 0.0261 \\
\hline - Length of stay in ICU in days & $15(3-44)$ & $11(2-36)$ & $22(3-50)$ & 0.0161 \\
\hline - SAPS2 & $42(27-60)$ & $49(31-77)$ & $37(23-54)$ & $<0.0001$ \\
\hline - In-ICU survival, $n(\%)$ & $496(67.1)$ & $239(61.9)$ & $257(72.8)$ & 0.0022 \\
\hline \multicolumn{5}{|l|}{ Nephrotoxic in ICU } \\
\hline - Aminoglycoside during hospitalization & $188(25.4)$ & $81(21)$ & $107(30.3)$ & 0.0047 \\
\hline - Glycopeptide during hospitalization & $41(5.5)$ & $16(4.1)$ & $25(7.1)$ & 0.1138 \\
\hline - Contrast agent & $74(10)$ & $48(12.4)$ & $26(7.4)$ & 0.0299 \\
\hline
\end{tabular}

All data are expressed as median $\pm 25-75$ interquartile or percentage (\%)

$B M I$ body mass index, GCS Glasgow coma scale, CKD chronic kidney disease, CHT chronic hypertension, CHF chronic heart failure, TBSA total body surface area, SOFA sequential organ failure assessment, MAP mean arterial pressure, HbCO carboxy hemoglobin, ICU intensive care unit, AKI acute kidney injury, Severe AKI AKI stage 2 and $3, R R T$ renal replacement therapy, MAKE major associated kidney events, Shock in ICU catecholamine need during ICU stay, SAPS2 simplified acute physiology score 2 
Table 2 Multivariate analyses of factors associated with AKI and severe AKI

\begin{tabular}{|c|c|c|c|c|}
\hline Variable & Adjusted odds ratio & $\mathrm{LCl}$ & $\mathrm{UCl}$ & $p$ \\
\hline \multicolumn{5}{|l|}{$\overline{A K I}$} \\
\hline Hydroxocobalamin & 1.597 & 1.055 & 2.419 & 0.027 \\
\hline Severe burn & 2.91 & 1.841 & 4.601 & $<0.001$ \\
\hline SOFA score without renal item & 1.003 & 0.891 & 1.129 & 0.963 \\
\hline Prehospital GCS & 1.064 & 0.997 & 1.136 & 0.063 \\
\hline Aminoglycoside during hospitalization & 2.903 & 1.184 & 4.473 & $<0.001$ \\
\hline Glycopeptide during hospitalization & 1.731 & 0.773 & 3.877 & 0.182 \\
\hline Admission plasma lactate & 1.105 & 1.034 & 1.182 & 0.003 \\
\hline Age & 1.009 & 0.997 & 1.021 & 0.154 \\
\hline Peripheral arterial obstructive disease & 0.913 & 0.308 & 2.713 & 0.87 \\
\hline Diabetes mellitus & 1.487 & 0.726 & 3.046 & 0.278 \\
\hline Chronic hypertension & 2.134 & 1.248 & 3.649 & 0.006 \\
\hline CKD & 0.947 & 0.119 & 7.504 & 0.959 \\
\hline Prehospital cardiac arrest & 0.418 & 0.025 & 7.096 & 0.546 \\
\hline Vasopressor at admission & 1.778 & 0.93 & 3.396 & 0.081 \\
\hline Maximum CPK & 1.081 & 0.997 & 1.242 & 0.269 \\
\hline Contrast agent & 1.445 & 0.803 & 2.601 & 0.219 \\
\hline SAPS2 & 1.021 & 1.006 & 1.036 & 0.009 \\
\hline Center & 1.014 & 0.976 & 1.053 & 0.484 \\
\hline Interaction between prehospital cardiac arrest and hydroxocobalamin & 2.245 & 0.125 & 40.367 & 0.583 \\
\hline \multicolumn{5}{|l|}{ Severe AKI } \\
\hline Hydroxocobalamin & 1.772 & 1.137 & 2.762 & 0.012 \\
\hline Age & 1.006 & 0.993 & 1.019 & 0.394 \\
\hline Peripheral arterial obstructive disease & 0.552 & 0.183 & 1.668 & 0.292 \\
\hline Diabetes mellitus & 1.201 & 0.582 & 2.479 & 0.619 \\
\hline Chronic hypertension & 2.045 & 1.168 & 3.579 & 0.012 \\
\hline Prehospital cardiac arrest & 0.775 & 0.043 & 14.12 & 0.863 \\
\hline Severe burn & 2.157 & 1.276 & 3.645 & 0.004 \\
\hline SOFA score at admission without renal item & 1.047 & 0.924 & 1.185 & 0.471 \\
\hline CKD & 2.407 & 0.285 & 20.299 & 0.418 \\
\hline Vasopressor at admission & 1.298 & 0.653 & 2.579 & 0.456 \\
\hline Prehospital GCS & 1.04 & 0.973 & 1.11 & 0.248 \\
\hline Admission plasma lactate & 1.151 & 1.062 & 1.248 & 0.001 \\
\hline Maximum CPK & 1.099 & 0.904 & 1.337 & 0.324 \\
\hline Aminoglycoside during hospitalization & 2.418 & 1.539 & 3.801 & $<0.001$ \\
\hline Contrast agent & 0.889 & 0.476 & 1.663 & 0.713 \\
\hline Glycopeptide during hospitalization & 2.873 & 1.318 & 6.261 & 0.008 \\
\hline SAPS2 & 1.02 & 1.006 & 1.035 & 0.006 \\
\hline Center & 1.042 & 0.998 & 1.089 & 0.061 \\
\hline Interaction between prehospital cardiac arrest and hydroxocobalamin & 0.412 & 0.02 & 8.331 & 0.563 \\
\hline
\end{tabular}

AKI acute kidney injury, $L C l$ lower confidence interval, UCI upper confidence interval, $p p$ value, SOFA score sequential organ failure assessment, GCS Glasgow coma scale, CKD chronic kidney disease, CPK creatinine phosphokinase, SAPS2 simplified acute physiology score 2 


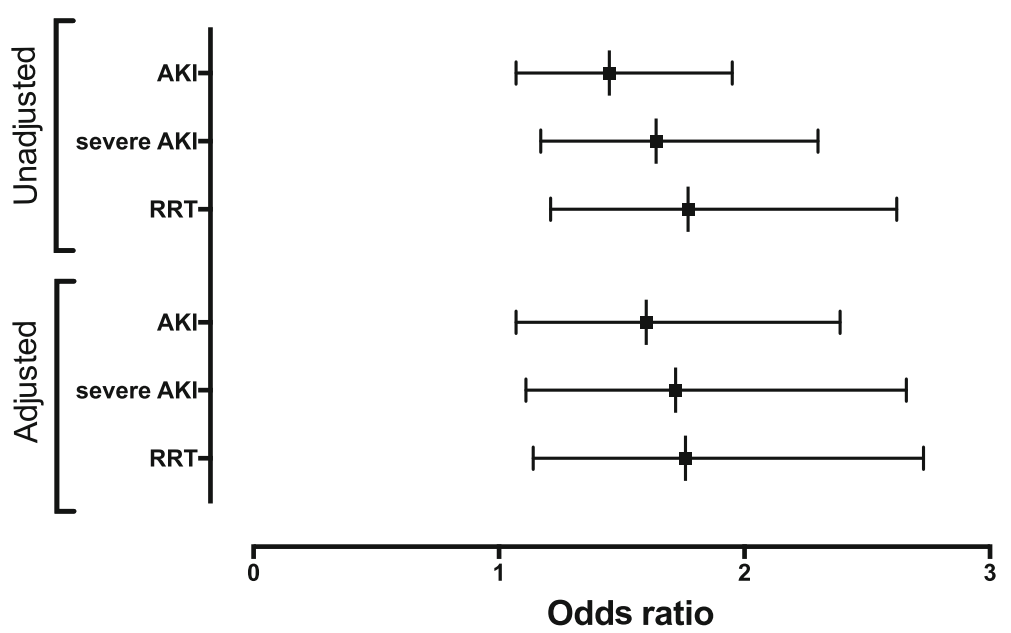

Fig. 1 Non-adjusted and adjusted odds ratio (lower confidence interval, upper confidence interval) of hydroxocobalamin for AKI (upper panel) and severe AKI (lower panel). Adjusted on the following variables: age, peripheral arterial obstructive disease, diabetes mellitus, chronic hypertension, chronic kidney disease, prehospital cardiac arrest, severe burn, SOFA score without kidney item, vasopressors at admission, prehospital Glasgow coma scale, plasmatic lactate level at admission, maximum creatinine phosphokinase plasmatic level, contrast agent, use of vancomycin and aminoglycosides, and simplified acute physiology score 2

Missing data were handled using multivariate imputation by chained equations (mice package for R, $50 \mathrm{im}$ putations) [9].

Because plasma lactate level was shown to correlate with cyanide, we performed subgroup analysis in patients with plasma lactate level at admission above median of the entire cohort and above $8 \mathrm{mmol} / \mathrm{L}[10,11]$. A subgroup analysis was also performed in patients with severe burns.

\section{Results}

Among 854 patients with smoke inhalation, 739 were included in the analysis after exclusion of patients discharged at home within $24 \mathrm{~h}$. Three hundred eighty-six (55.2\%) patients received hydroxocobalamin. Patient's characteristics and comparison between patients who received hydroxocobalamin and those who did not are presented in Table 1 . The number of patients per center is summarized in Additional file 2: Table S2.

\section{Acute kidney injury}

Two hundred eighty-eight (39\%) patients developed AKI in the first week, including $186(25.2 \%)$ patients with severe AKI. In univariate analysis, the use of hydroxocobalamin was associated with AKI, severe AKI, and RRT (Table 1). After adjusting for potential confounders, hydroxocobalamin remained associated with AKI and severe AKI and RRT (Table 2, Fig. 1 and Additional file 3: Table S3). Severe burns, aminoglycoside administration, admission plasma lactate level, chronic hypertension, and SAPS2 were also associated with AKI (Table 2).

Three hundred and thirteen (42.4\%) patients met the criteria for MAKE during ICU stay. Hydroxocobalamin was not associated with the risk of MAKE in multivariate analysis $(\mathrm{OR}=0.784, \mathrm{LCI}=0.456, \mathrm{UCI}=$ $1.349, p=0.379)$. Factors associated with MAKE in ICU are summarized in Additional file 4: Table S4.

\section{ICU mortality}

Mortality in ICU was $32.9 \%(N=243)$. Patients who received hydroxocobalamin had higher severity scores and higher mortality rate. Factors associated with mortality in univariate analysis are summarized in Table 3 and Fig. 2. In multivariate analysis, hydroxocobalamin was not associated with survival (OR = 1.114, $\mathrm{LCI}=0.691, \mathrm{UCI}=1.797, p=0.657$ ). Age, severe burns, SAPS2, plasma lactate level at admission, and the center were associated with mortality in ICU (Table 4). Three hundred and ninety-two patients (53\%) had admission plasma lactate level above the median $($ median $=3.0[1.8-5.2] \mathrm{mmol} / \mathrm{L})$, and $74 \mathrm{pa}-$ tients had admission plasma lactate level $\geq 8 \mathrm{mmol} / \mathrm{L}$ $($ median $=10.5 \quad[8.9-12.8] \quad \mathrm{mmol} / \mathrm{L}) \quad($ among 681 (92.2\%) patients with plasma lactate available at admission, Additional file 5: Table S5). No association between hydroxocobalamin use and survival was observed after adjustment for confounding factors in the subgroups of patients with admission plasma lactate level above the median $(\mathrm{OR}=0.76$; $\mathrm{LCI}=0.398, \mathrm{UCI}=$ $1.451, p=0.403)$ or in the group of patients with admission plasma lactate level $\geq 8 \mathrm{mmol} / \mathrm{L} \quad(\mathrm{OR}=2.604$, 
Table 3 Patient characteristics

\begin{tabular}{|c|c|c|c|c|}
\hline Characteristics & All patients, $N=739$ & Survivors, $N=496$ & Non-survivors, $N=243$ & $p$ \\
\hline \multicolumn{5}{|l|}{ At admission } \\
\hline - Age in years & $50(36-63)$ & $46(33-59)$ & $56(43-72)$ & $<0.0001$ \\
\hline - Sex female, $n(\%)$ & $271(36.7)$ & $180(36.3)$ & $91(37.4)$ & 0.8214 \\
\hline - BMl in $\mathrm{kg} / \mathrm{m}^{2}$ & $25(22-28)$ & $24(22-28)$ & $25(22-29)$ & 0.0822 \\
\hline - Prehospital cardiac arrest (\%) & $46(6.2)$ & $11(2.2)$ & $35(14.4)$ & $<0.0001$ \\
\hline - Prehospital GSC /15 & $15(9-15)$ & $15(13-15)$ & $14(3-15)$ & $<0.0001$ \\
\hline \multicolumn{5}{|l|}{ Comorbidities } \\
\hline - CKD, n (\%) & $6(0.8)$ & $2(0.4)$ & $4(1.6)$ & 0.0948 \\
\hline - Hypertension, n (\%) & $141(19.1)$ & $81(16.3)$ & $60(24.7)$ & 0.0088 \\
\hline - Diabetes mellitus, n (\%) & $54(7.3)$ & $28(5.6)$ & $26(10.7)$ & 0.0198 \\
\hline - CAOD, $n(\%)$ & $22(3)$ & $7(1.4)$ & $15(6.2)$ & 0.0008 \\
\hline$-\mathrm{CHF}, n(\%)$ & $33(4.5)$ & $20(4)$ & $13(5.3)$ & 0.4858 \\
\hline \multicolumn{5}{|l|}{ Burn characteristic } \\
\hline - Burn, $n(\%)$ & $577(78.1)$ & $357(72)$ & $220(90.5)$ & $<0.0001$ \\
\hline - TBSA \% & $20(3-47)$ & $12(0-30)$ & $50(20-73)$ & $<0.0001$ \\
\hline - 3rd degree TBSA \% & $9(0-30)$ & $2(0-15)$ & $33(10-58)$ & $<0.0001$ \\
\hline SOFA at admission & $4(1-7)$ & $2(1-5)$ & $7(3-10)$ & $<0.0001$ \\
\hline MAP in $\mathrm{mmHg}$ & $86(72-101)$ & $89(76-102)$ & $80(62-97)$ & $<0.0001$ \\
\hline Vasopressor, n (\%) & $226(30.6)$ & $90(18.1)$ & $136(56)$ & $<0.0001$ \\
\hline Hydroxocobalamin, $n$ (\%) & $386(52.2)$ & $239(48.2)$ & $147(60.5)$ & 0.0021 \\
\hline $\mathrm{HbCO} \%$ & $4(2-10)$ & $4(2-11)$ & $3(2-7)$ & 0.0323 \\
\hline \multicolumn{5}{|l|}{ Biological data } \\
\hline - Plasmatic lactate in mmol/L & $3.0(1.8-5.2)$ & $2.5(1.4-3.8)$ & $4.8(3-7.6)$ & $<0.0001$ \\
\hline - Serum creatinine in $\mu \mathrm{mol} / \mathrm{L}$ & $76(59-101)$ & $71(56-88)$ & $100(72-123)$ & $<0.0001$ \\
\hline - Maximal serum creatinine in $\mu \mathrm{mol} / \mathrm{L}$ & $100(73-162)$ & $84(68-113)$ & $137(102-212)$ & $<0.0001$ \\
\hline Inhalation fibroscopic status (\%) & $305(41.3)$ & $175(35.3)$ & $130(53.5)$ & $<0.0001$ \\
\hline - Grade $0, n$ & $1(0.1)$ & $1(0.2)$ & $0(0)$ & 1 \\
\hline - Grade $1, n$ & $121(16.4)$ & $90(18.2)$ & $31(12.8)$ & 0.0795 \\
\hline - Grade $2, n$ & $110(14.9)$ & $67(13.5)$ & $43(17.7)$ & 0.1638 \\
\hline - Grade $3, n$ & $73(9.9)$ & $17(3.4)$ & $56(23.1)$ & $<0.0001$ \\
\hline \multicolumn{5}{|l|}{ - During ICU hospitalization } \\
\hline - AKI in the first week, $n(\%)$ & $288(39)$ & $126(25.4)$ & $162(66.7)$ & $<0.0001$ \\
\hline \multicolumn{5}{|l|}{ - Stage of AKI day 7} \\
\hline - Stage $1, n(\%)$ & $102(13.8)$ & $63(12.7)$ & $39(16)$ & 0.2601 \\
\hline - Stage $2, n(\%)$ & $39(5.3)$ & $16(3.2)$ & $23(9.5)$ & 0.0007 \\
\hline - Stage 3, n (\%) & $147(19.9)$ & $47(9.5)$ & $100(41.2)$ & $<0.0001$ \\
\hline - Severe AKI & $186(25.2)$ & $63(12.7)$ & $123(50.6)$ & $<0.0001$ \\
\hline - RRT at day $7, n(\%)$ & $136(18.8)$ & $44(8.9)$ & $92(37.9)$ & $<0.0001$ \\
\hline - RRT in ICU, $n(\%)$ & $183(24.8)$ & $58(11.7)$ & $125(51.4)$ & $<0.0001$ \\
\hline - MAKE, n (\%) & $313(42.4)$ & $69(13.9)$ & $243(100)$ & $<0.0001$ \\
\hline - Shock in ICU, $n(\%)$ & $402(54.4)$ & $191(38.5)$ & $211(86.8)$ & $<0.0001$ \\
\hline - Length of stay in ICU & $15(3-44)$ & $25(4-50)$ & $6(1-24)$ & 0.0001 \\
\hline - SAPS2 & $42(27-60)$ & $32(22-46)$ & $61(46-75)$ & $<0.0001$ \\
\hline
\end{tabular}

Nephrotoxic in ICU 
Table 3 Patient characteristics (Continued)

\begin{tabular}{lllll}
\hline Characteristics & All patients, $N=739$ & Survivors, $N=496$ & Non-survivors, $N=243$ & $p$ \\
\hline - Aminoglycoside & $188(25.4)$ & $115(23.2)$ & $73(42.9)$ & 0.0548 \\
- Vancomycin & $41(5.5)$ & $22(4.4)$ & $19(7.8)$ & 0.4011 \\
- Contrast product & $74(10)$ & $41(8.3)$ & $33(13.6)$ & 0.0331 \\
\hline
\end{tabular}

All data are expressed as median $\pm 25-75$ interquartile or percentage (\%)

$B M I$ body mass index, GCS Glasgow coma scale, $C K D$ chronic kidney disease, $C A O D$ chronic arterial occlusive disease, $C H F$ chronic heart failure, $T B S A$ total body surface area, SOFA sequential organ failure assessment, MAP mean arterial pressure, $H b C O$ carboxy hemoglobin, $I C U$ intensive care unit, $A K I$ acute kidney injury, $R R T$ renal replacement therapy, MAKE major associated kidney events, SAPS2 simplified acute physiology score 2

$\mathrm{LCI}=0.361, \quad \mathrm{UCI}=18.79, \quad p=0.336)$. In multivariate analysis, hydroxocobalamin was neither associated with survival $(\mathrm{OR}=0.85, \mathrm{LCI}=0.5, \mathrm{UCI}=1.447, p=$ 0.549 ) among 405 (54.8\%) patients with severe burns (Additional file 6: Table S6).

\section{Discussion}

In this retrospective, multicenter study, we observed a higher risk of AKI and severe AKI associated with administration of hydroxocobalamin after adjustment for potential confounding factors. Hydroxocobalamin was not associated with improved survival.

Cyanide poisoning has been suspected to account for deaths after smoke inhalation [12]. Hydroxocobalamin $\left(\right.$ Cyanokit $^{\oplus}$, Merck Santé SAS) is approved by the Food and Drug Administration for the treatment of cyanide poisoning. Hydroxocobalamin chelates cyanide to form cyanocobalamin, which is excreted by the kidneys. Experts have advocated the use of cyanide antidotes after smoke inhalation with suspected cyanide intoxication. While preclinical data have suggested improved hemodynamics with hydroxocobalamin in animal models of cyanide intoxication, clinical data are very limited. In two retrospective studies, Borron et al. and Fortin et al. described the outcome of patients receiving hydroxocobalamin after smoke inhalation injury. However, the absence of control groups precluded drawing any conclusion with respect to the impact of hydroxocobalamin on outcome [13, 14]. Nguyen et al. reported that the use of hydroxocobalamin was associated with fewer episodes of pneumonia while mortality was unaffected [15]. However, the association between the prevention of pneumonia lies on very low level of evidence. Other factors, especially with respect to pneumonia preventive strategies, may have accounted for the observation of lower incidence of pneumonia in this before-andafter retrospective study.

In the current study, we observed an association between hydroxocobalamin and the risk of AKI and severe AKI. These results further suggest the potential nephrotoxicity of the drug. We previously showed that hydroxocobalamin induces oxaluria with a risk of oxalate nephropathy in burn patients [4]. Kidney biopsies confirmed renal calcium oxalate crystal deposits. Oxaluria was also reported in healthy volunteers and animals receiving hydroxocobalamin [16]. Nitric oxide chelation could represent an additional mechanism of renal toxicity of hydroxocobalamin. In the absence of cyanide, hydroxocobalamin binds to nitric oxide. Nitric oxide is a key factor of the renal microcirculatory regulation, and inhibition of the nitric oxide pathway was shown to impair renal perfusion and oxygenation and cause kidney damage [17-19].

Cyanide is a rapidly lethal mitochondrial poison. The plasma cyanide level is difficult to measure and not readily available, and none of the patients included in this study had a plasma cyanide dosage. Increased serum lactate level $>8 \mathrm{mmol} / \mathrm{L}$ was reported to be a fair surrogate biomarker of cyanide poisoning as a biomarker of mitochondrial dysfunction [10]. In our study, hydroxocobalamin had no impact in the subgroup of patients with high plasma lactate level. The lack of evidence of any association between hydroxocobalamin and survival in our study and the risk of AKI question the risk-benefit ratio in these patients. Of note, hydroxocobalamin costs about $€ 1000 /$ $\$ 1200$ per vial.

We acknowledge the limitations of our study. First, the retrospective nature introduced some bias. Performing a randomized control trial in this setting would be highly difficult due to the low incidence of smoke inhalation and the existing cognitive biases toward the potential protective effects of hydroxocobalamin. Second, the relative low number of patients with very high plasma lactate level precludes drawing firm conclusion in patients with a high probability of cyanide poisoning and in most severe patients. Third, we could not confirm cyanide levels in any patient, which makes it hard to determine if hydroxocobalamin could benefit patients with confirmed cyanide poisoning. Finally, rhabdomyolysis may be a confounding factor with the elevated serum creatinine. However, we did not find any correlation between admission serum creatinine, maximal serum creatinine at day 7 or during hospitalization in ICU, and the pic of creatinine phosphokinase. 


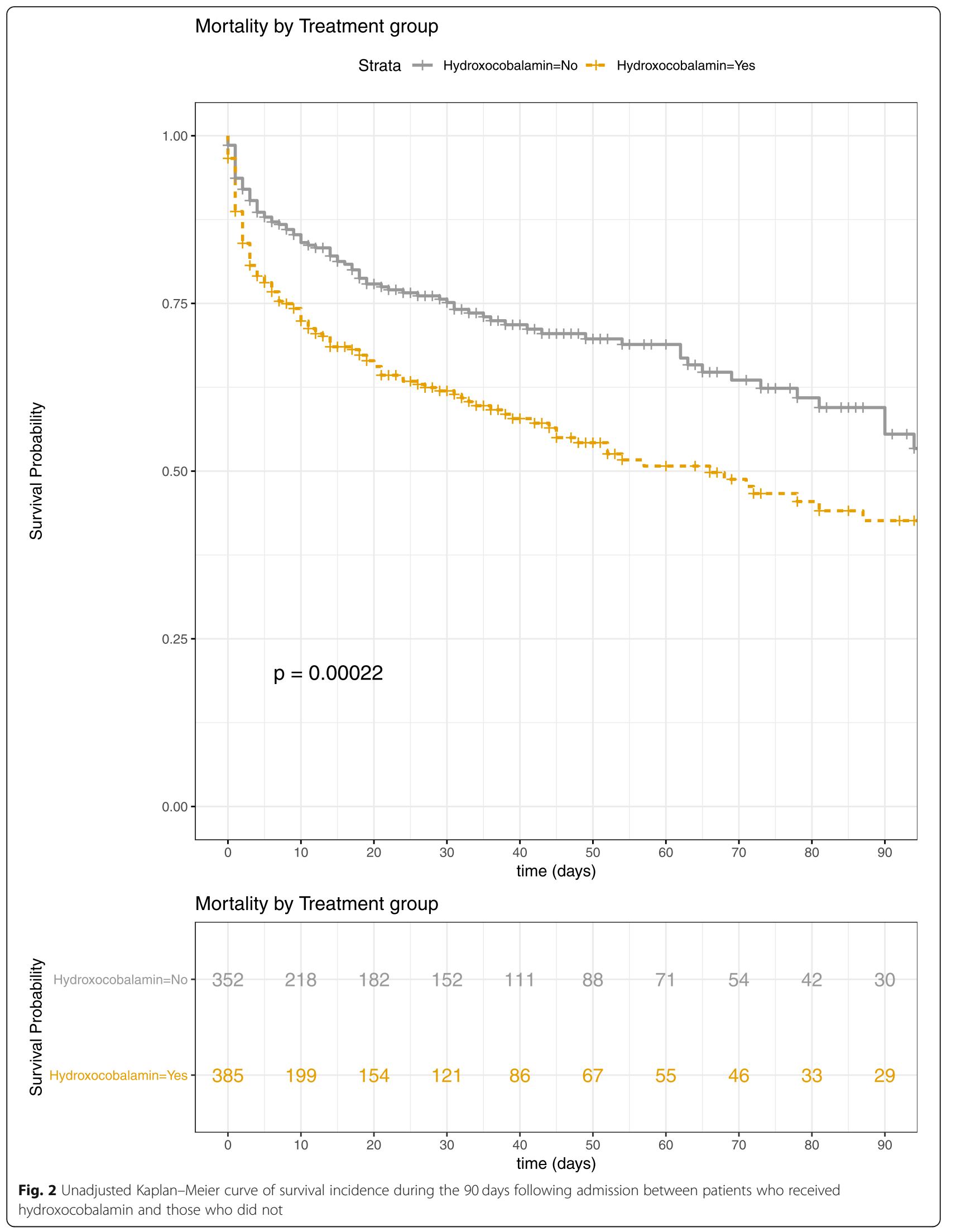


Table 4 Multivariate analyses of factors associated with ICU mortality

\begin{tabular}{lllll}
\hline ICU mortality & \multicolumn{1}{l}{ Adjusted } & $\mathrm{LCl}$ & $\mathrm{UCl}$ & $p$ \\
\hline Variable & odds ratio & & & \\
\hline Hydroxocobalamin & 1.114 & 0.691 & 1.797 & 0.657 \\
Age & 1.037 & 1.023 & 1.05 & $<0.001$ \\
Prehospital cardiac arrest & 1.091 & 0.07 & 17.126 & 0.95 \\
Severe burn & 4.792 & 2.665 & 8.617 & $<0.001$ \\
SOFA score at admission & 1.074 & 0.942 & 1.225 & 0.283 \\
Admission plasma lactate & 1.256 & 1.154 & 1.366 & $<0.001$ \\
Vasopressors at admission & 1.571 & 0.737 & 3.346 & 0.241 \\
Prehospital GCS & 1.033 & 0.961 & 1.11 & 0.383 \\
SAPS2 & 1.039 & 1.02 & 1.059 & $<0.001$ \\
Center & 1.084 & 1.033 & 1.137 & 0.001 \\
Interaction between & 6.327 & 0.354 & 112.993 & 0.209
\end{tabular}

prehospital cardiac

arrest and hydroxocobalamin

ICU intensive care unit, $\mathrm{LCl}$ lower confidence interval, UCl upper confidence interval, $p p$ value, SOFA score sequential organ failure assessment score, GCS Glasgow coma scale, SAPS2 simplified acute physiology score 2

\section{Conclusion}

In this multicenter observational study of ICU patients with smoke inhalation, administration of hydroxocobalamin was independently associated with AKI and showed no association with survival. The role of hydroxocobalamin following smoke inhalation needs further consideration and critical appraisal.

\section{Supplementary information}

Supplementary information accompanies this paper at https://doi.org/10. 1186/s13054-019-2706-0

Additional file 1 : Table $\mathbf{S 1}$. Coding system for smoke inhalation.

Additional file $\mathbf{2}$ : Table S2. Number of patients from each centers.

Additional file $\mathbf{3}$ : Table S3. Multivariate analysis of factors associated with RRT.

Additional file 4 : Table S4. Multivariate analysis of factors associated with major adverse kidney events.

Additional file 5 : Table S5. Comparison between admission lactate quartile.

Additional file $\mathbf{6}$ : Table S6. Comparison between severely burn and non-severely burn patients.

\section{Abbreviations}

AKI: Acute kidney injury; Cis: Confidence intervals; ICU: Intensive care unit; KDIGO: Kidney Disease Improving Global Outcome; MAKE: Major associated kidney events; RRT: Renal replacement therapy; SCreat: Serum creatinine; TBSA: Total body surface area

\section{Acknowledgements}

None

\section{Authors' contributions}

FD designed the study, collected the data, interpreted the data, and drafted the manuscript. CH collected the data and drafted the manuscript. LD collected the data and drafted the manuscript. $C T$ collected the data and drafted the manuscript. LMr collected the data and drafted the manuscript $J C$ collected the data and drafted the manuscript. DA collected the data and drafted the manuscript. EP collected the data and drafted the manuscript. DM collected the data and drafted the manuscript. SW collected the data and drafted the manuscript. DDDL collected the data and drafted the manuscript. AK collected the data and drafted the manuscript. JT collected the data and drafted the manuscript. FR collected the data and drafted the manuscript. KK collected the data and drafted the manuscript. EP collected the data and drafted the manuscript. GS collected the data and drafted the manuscript. FB collected the data and drafted the manuscript. JMC collected the data and drafted the manuscript. TC collected the data and drafted the manuscript. DD collected the data and drafted the manuscript. NT collected the data and drafted the manuscript. BS collected the data and drafted the manuscript. EG collected the data and drafted the manuscript. TL collected the data and drafted the manuscript. AH collected the data and drafted the manuscript. BM collected the data and drafted the manuscript. TL collected the data and drafted the manuscript. VM interpreted the data and drafted the manuscript. RP performed the statistical analysis, interpreted the data, and drafted the manuscript. ML designed the study, collected the data, interpreted the data, supervised the study, and drafted the manuscript. All authors read and approved the final manuscript.

\section{Funding}

The study was supported by a grant from the "Fondation des gueules cassées" to Matthieu Legrand.

\section{Availability of data and materials}

The datasets used and/or analyzed during the current study are available from the corresponding author on reasonable request.

Ethics approval and consent to participate

The study protocol was approved by our local research ethical committee (Comité de Protection des Personnes 2013/17NICB).

\section{Consent for publication}

Not applicable.

\section{Competing interests}

The authors declare that they have no competing interests.

\section{Author details}

1'Department of Anesthesiology and Critical Care and Burn Unit, AP-HP, GH Saint Louis-Lariboisière, Paris, France. ${ }^{2}$ UMR INSERM 942, Institut National de la Santé et de la Recherche Médicale (INSERM), Paris, France. ${ }^{3} \mathrm{~F}-\mathrm{CRIN}$, INICRCT network, Paris, France. ${ }^{4}$ Paris Diderot University, F-75475 Paris, France. ${ }^{5}$ Burn Center, Percy Military Teaching Hospital, BP 406, 101, avenue Henri-Barbusse, 92141 Clamart CEDEX, France. ${ }^{6}$ Intensive Care Unit and Hyperbaric Center, Lille University Hospital, F-59037 Lille CEDEX, France. ${ }^{7}$ General ICU, Service de Réanimation, Hôpital Raymond Poincaré, Laboratory of Infection and Inflammation, U1173, AP-HP, University of Versailles SQY and INSERM, 104 Boulevard Raymond Poincaré, 92380 Garches, France. ${ }^{8}$ Centre de traitement des grands brûlés Hopital de la Conception APHM, 147 boulevard Baille, 13005 Marseille, France. ${ }^{9}$ Intensive Care Unit, Anaesthesia and Critical Care Department, Hôtel Dieu-HME, CHU Nantes, Nantes, France. ${ }^{10} \mathrm{Centre}$ de traitement des grands brûlés Hopital de Mercy, 1 Allée du Château, 57245 Ars-Laquenexy-C.H.R Metz-, Thionville, France.

${ }^{11}$ Anesthesiology and Critical Care Medicine, Hospices Civils de Lyon-Université Claude Bernard Lyon 1, Lyon, France. ${ }^{12}$ Anesthesiology and Critical Care Medicine, CHU Bordeaux, Place Amélie Raba Léon, 33000 Bordeaux, France. ${ }^{13}$ Intensive Care Medicine Department, University of Montpellier Lapeyronie Hospital, 371, Av Doyen Gaston Giraud, 34295 Montpellier, France. ${ }^{14}$ Intensive Care Medicine Department, CHU de Rennes, 2 rue Henri Le Guilloux, 35033 Rennes CEDEX 9, France. ${ }^{15}$ Service de réanimation médico-chirurgicale, Groupe Hospitalier du Havre-Hôpital Jacques Monod, Montivilliers, France. ${ }^{16}$ Medical Intensive Care Unit, La Source Hospital, CHR Orléans, Orléans, France. ${ }^{17}$ Department of Perioperative Medicine, University Hospital of Clermont-Ferrand, Clermont-Ferrand, France. ${ }^{18}$ Department of Anesthesiology and Critical Care, Rouen University Hospital, Rouen, France. ${ }^{19}$ Normandie Univ, UNIROUEN, INSERM U1096, Rouen, France. ${ }^{20}$ Medical Intensive Care Unit, Caen University Hospital, Avenue côte de 
Nacre, 14033 Caen CEDEX, France. ${ }^{21}$ Service de Réanimation Médicale, Centres Hospitaliers Universitaires Grenoble Alpes, Grenoble, France. ${ }^{22}$ Service de Réanimation Médicale Polyvalente, Centre Hospitalier Public du Cotentin, BP 208, 50102 Cherbourg-Octeville, France. ${ }^{23}$ Service de Réanimation Médicale, Hôpital Européen Georges-Pompidou, Assistance Publique-Hôpitaux de Paris, Paris, France. ${ }^{24}$ Faculté de Médecine, Université Paris Descartes, Paris, France. ${ }^{25}$ Département des urgences, service des urgences, SAMU, CHU de Limoges, 87042 Limoges CEDEX, France. ${ }^{26}$ Inserm CIC 1435, 87042 Limoges, France. ${ }^{27}$ Intensive Care Unit, Saint Louis Hospital, La Rochelle, France. ${ }^{28}$ Service de réanimation médicale et toxicologie, Hôpital Lariboisière, Assistance Publique-Hôpitaux de Paris, Paris, France. ${ }^{29}$ Service d'hépato gastro entérologie Hôpital Cochin, hépato Cochin, Assistance Publique-Hôpitaux de Paris, Paris, France. ${ }^{30}$ Department of Anesthesia and perioperative care, University of California San Francisco, San Francisco, USA. ${ }^{31}$ Department of Anesthesiology and Perioperative care Parnassus hospital, UCSF, San Francisco, USA.

Received: 6 September 2019 Accepted: 16 December 2019

Published online: 23 December 2019

\section{References}

1. Lawson-Smith P, Jansen EC, Hyldegaard O. Cyanide intoxication as part of smoke inhalation - a review on diagnosis and treatment from the emergency perspective. Scand J Trauma Resusc Emerg Med. 2011;19:14.

2. Petrikovics I, Budai M, Kovacs K, Thompson DE. Past, present and future of cyanide antagonism research: from the early remedies to the current therapies. World J Methodol. 2015;5:88-100.

3. Anseeuw K, Delvau N, Burillo-Putze G, De laco F, Geldner G, Holmström P, et al. Cyanide poisoning by fire smoke inhalation: a European expert consensus. Eur J Emerg Med. 2013;20:2-9.

4. Legrand M, Michel T, Daudon M, Benyamina M, Ferry A, Soussi S, et al. Risk of oxalate nephropathy with the use of cyanide antidote hydroxocobalamin in critically ill burn patients. Intensive Care Med. 2016;42:1080-1.

5. Legrand M, Mallet V. Intravenous hydroxocobalamin and crystal nephropathy. Nat Rev Nephrol. 2017;13:593.

6. Kellum JA, Lameire N, Aspelin P, Barsoum RS, Burdmann EA, Goldstein SL, et al. Work group membership. Kidney Int. 2012;2:1.

7. Monafo W. Initial management of burns. N Engl J Med. 1996;335(21):1581-6.

8. Chou SH, Lin S-D, Chuang H-Y, Cheng Y-J, Kao EL, Huang M-F. Fiber-optic bronchoscopic classification of inhalation injury: prediction of acute lung injury. Surg Endosc. 2004;18:1377-9.

9. Bartlett JW, Seaman SR, White IR, Carpenter JR, for the Alzheimer's Disease Neuroimaging Initiative*. Multiple imputation of covariates by fully conditional specification: accommodating the substantive model. Stat Methods Med Res. 2015;24:462-87.

10. Baud FJ, Borron SW, Mégarbane B, Trout H, Lapostolle F, Vicaut E, et al. Value of lactic acidosis in the assessment of the severity of acute cyanide poisoning. Crit Care Med. 2002;30:2044-50.

11. Baud FJ, Haidar MK, Jouffroy R, Raphalen J-H, Lamhaut L, Carli P. Determinants of lactic acidosis in acute cyanide poisonings. Crit Care Med. 2018;46:e523-9.

12. Kadri SS, Miller AC, Hohmann S, Bonne S, Nielsen C, Wells C, et al. Risk factors for in-hospital mortality in smoke inhalation-associated acute lung injury: data from 68 United States hospitals. Chest. 2016;150:1260-8.

13. Borron SW, Baud FJ, Barriot P, Imbert M, Bismuth C. Prospective study of hydroxocobalamin for acute cyanide poisoning in smoke inhalation. Ann Emerg Med. 2007;49:794-801.e2.

14. Fortin J-L, Giocanti J-P, Ruttimann M, Kowalski J-J. Prehospital administration of hydroxocobalamin for smoke inhalation-associated cyanide poisoning: 8 years of experience in the Paris fire brigade. Clin Toxicol. 2006;44:37-44.

15. Nguyen L, Afshari A, Kahn SA, McGrane S, Summitt B. Utility and outcomes of hydroxocobalamin use in smoke inhalation patients. Burns. 2017:43(1): 107-13.

16. EMD Serono, A Division of EMD Inc., Canada. CYANOKIT ${ }^{\oplus}$ Product Monograph. 2014. Available from: http://webprod.hc-sc.gc.ca/dpd-bdpp/ index-eng.jsp. Accessed 30 Sept 2014.

17. Legrand M, Mik EG, Johannes T, Payen D, Ince C. Renal hypoxia and dysoxia after reperfusion of the ischemic kidney. Mol Med Camb Mass. 2008;14:502-16.

18. Legrand M, Almac E, Mik EG, Johannes T, Kandil A, Bezemer R, et al. L-NIL prevents renal microvascular hypoxia and increase of renal oxygen consumption after ischemia-reperfusion in rats. Am J Physiol Renal Physiol. 2009;296:F1109-17.

19. Soussi S, Dépret F, Benyamina M, Legrand M. Early hemodynamic management of critically ill burn patients. Anesthesiology. 2018;129:583-9.

\section{Publisher's Note}

Springer Nature remains neutral with regard to jurisdictional claims in published maps and institutional affiliations.
Ready to submit your research? Choose BMC and benefit from:

- fast, convenient online submission

- thorough peer review by experienced researchers in your field

- rapid publication on acceptance

- support for research data, including large and complex data types

- gold Open Access which fosters wider collaboration and increased citations

- maximum visibility for your research: over $100 \mathrm{M}$ website views per year

At BMC, research is always in progress.

Learn more biomedcentral.com/submissions 